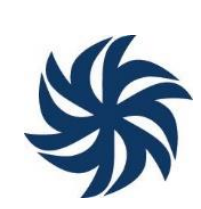

\title{
“COMO SE INFORMA, DEPUTADO?” HÁBITOS DE USO DOS MEDIA POR PARTE DOS DEPUTADOS ESTADUAIS DO PARANÁ ${ }^{1}$
}

\section{"HOW DO YOU GET INFORMATION, PARLIAMENTARIAN?" PATTERNS OF MEDIA USE BY STATE PARLIAMENT MEMBERS \\ “¿CÓMO USTED SE INFORMA, DIPUTADO?” LOS HÁBITOS DE CONSUMO DE LOS MEDIOS DE COMUNICACIÓN POR DIPUTADOS EN PARANÁ}

\author{
Andressa Butture Kniess ${ }^{2}$ \\ Mylena Peixoto de Mattos $^{3}$ \\ Pedro Henrique Leite ${ }^{4}$ \\ Francisco Paulo Jamil Marques ${ }^{5}$
}

\begin{abstract}
Resumo: O artigo propõe três objetivos: investigar quais instituições jornalísticas são mais utilizadas por parlamentares com a finalidade de consumir informações; verificar o grau de confiança que os representantes relatam depositar nos media; e examinar o grau de eficiência que deputados atribuem a diferentes plataformas midiáticas com vistas à autopromoção; a partir dos resultados de um survey presencial aplicado aos deputados que exerciam mandato na Assembleia Legislativa do Paraná (ALEP) em 2016. As formas de uso e variações de confiança nos media são diagnosticadas levando-se em conta variáveis independentes de natureza política e pessoal. Descobriu-se que os deputados se informam prioritariamente a partir de uma instituição jornalística local; além disso, eles tendem a considerar as redes sociais digitais muito eficientes para promoção política.
\end{abstract}

Palavras-chave: Comunicação; Representação; Política; Parlamentares; Survey.

Abstract: This article has three main objectives: to investigate which journalistic institutions are most used by parliamentarians to consume information; verify the degree of confidence that representatives have in the media; and to examine the degree of efficiency that MPs attribute to different media platforms regarding self-

\footnotetext{
${ }^{1}$ Uma versão anterior deste trabalho foi apresentada no $41^{\circ}$ Encontro Anual da ANPOCS.

2 Mestre em Ciência Política pela Universidade Federal do Paraná. Doutoranda em Ciência Política pela mesma instituição. Integrante do Grupo de Pesquisa em Comunicação, Política e Tecnologia - PONTE. Bolsista CAPES. E-mail: andressakniess@gmail.com

${ }^{3}$ Mestre em Ciência Política pela Universidade Federal do Paraná. E-mail: mylenamattos.2@gmail.com

4 Graduado na linha de Ciência Política no curso de bacharelado em Ciências Sociais pela Universidade Federal do Paraná. Integrante do Grupo de Pesquisa em Comunicação, Política e Tecnologia - PONTE. E-mail: pedrohenri.leite@gmail.com

${ }^{5}$ Professor e Pesquisador da Universidade Federal do Paraná. Bolsista de Produtividade em Pesquisa do CNPq. Integrante do Comitê Gestor do Instituto Nacional de Ciência e Tecnologia em Democracia Digital (INCT.DD). Líder do Grupo de Pesquisa em Comunicação, Política e Tecnologia - PONTE. E-mail: marquesjamil@gmail.com
} 
promotion; based on the results of a face-to-face survey applied to the deputies who were in office in the Legislative Assembly of Paraná (ALEP) in 2016. The forms of use and variations of trust in the media are studied taking into account political and personal independent variables. We found out that representatives prefer a local journalistic institution to get information; in addition, they tend to consider digital social networks as very efficient for political promotion.

Keywords: Communication; Representation; Politics; Congressmen; Survey.

Resumen: El artículo tiene tres objetivos: investigar cuales instituciones periodísticas son utilizadas por diputados para consumir informaciones; verificar el grado de confianza de los representantes en los medios; y analizar el grado de eficiencia que los diputados asignan a diferentes medios como herramientas de autopromoción. Los datos son provenientes de una encuesta presencial con los diputados que tenían un mandato en la Asamblea Legislativa de Paraná (ALEP) en 2016. Las maneras de uso y variaciones en la confianza en los medios son identificadas teniendo en cuenta variables independientes de carácter político y personal. Se ha encontrado que los diputados se informan de forma prioritaria por una institución periodística local; además, ellos tienden a considerar las redes sociales digitales como muy eficaces para promoción política.

Palabras clave: Comunicación; Representación; Política; Diputados; Encuesta.

\section{INTRODUÇÃO}

Pesquisas com foco em mídia parlamentar não são necessariamente novas. Coleman (1999), por exemplo, já reforçava, há quase duas décadas, a ideia de que os recursos de comunicação digital causariam efeitos diversos sobre a representação política. Bennett (2003), por sua vez, destacou o papel dos new media para a redução dos custos no que se refere à obtenção de informação e para a comunicação entre esfera civil e agentes do campo político. Já Goldbeck et al. (2010), assim como Lilleker e Jackson (2009), atentam, especificamente, para a utilização de redes sociais digitais por parte de congressistas. No caso brasileiro, Marques et al. (2014) investigaram as variáveis pessoais e políticas mais fortemente associadas ao uso do Twitter por parte de deputados federais. Chama a atenção, contudo, o fato de que ainda são raras as investigações que examinam os modos pelos quais os parlamentares se apropriam das plataformas midiáticas com o intuito de se informar.

Um dos poucos empreendimentos nesse sentido se refere ao levantamento "Mídia e Política”, elaborado desde 2008 pela agência FSB Comunicação. Tal relatório tem como foco "avaliar como se informam os tomadores de decisão no legislativo nacional" (FSB 
COMUNICAÇÕES, 2016, p. 5). O levantamento mais recente da referida agência elabora um diagnóstico sobre fontes de informação, instituições jornalísticas preferidas e opiniões dos parlamentares com atuação federal acerca da confiança e influência da mídia. Falta, porém, um estudo de alcance regional sobre a questão e que também esteja disposto a verificar a avaliação dos parlamentares acerca da eficiência dos media para promover suas imagens.

A fim de preencher tal lacuna na literatura brasileira, propõem-se os seguintes problemas de pesquisa neste artigo: 1) Em uma perspectiva que privilegia os modos de consumo de informação política, por meio de quais empresas jornalísticas os representantes eleitos dizem se informar? 2) Em quais plataformas de comunicação eles dizem confiar mais para adquirir informações? 3) Quais ferramentas de comunicação são consideradas as mais eficientes (no que se refere à autopromoção) por parte daqueles detentores de mandatos eletivos? O trabalho, portanto, está estruturado a partir dessas três dimensões (consumo, confiança e autopromoção), que são apresentadas em diferentes subseções e relacionadas na discussão dos resultados. O foco do estudo são os deputados estaduais do Paraná com mandato em exercício durante os meses de maio e junho de 2016. Os dados foram obtidos por meio de surveys aplicados juntamente aos próprios deputados.

$\mathrm{O}$ artigo está dividido em quatro partes. Primeiro é apresentada a revisão de literatura. Em seguida, o texto esclarece hipóteses e estratégias metodológicas. A terceira parte é concernente à apresentação dos dados, debruçando-se sobre os resultados quanto (a) aos modos como os deputados se informam; (b) como avaliam a confiabilidade que têm nas plataformas midiáticas; e (c) quais plataformas eles consideram mais eficientes para sua autopromoção política. Por fim, apresenta-se a discussão dos resultados e a conclusão.

\section{REVISÃO DE LITERATURA: O CONSUMO E O EMPREGO DOS MEDIA POR PARTE DE REPRESENTANTES POLÍTICOS}

A discussão sobre o consumo de informações por parte de agentes do campo político remonta os anos 1970 e 1980 (BIMBER, 1991), época em que um conjunto de pesquisas se dedicou a investigar a influência de diferentes fontes de dados sobre o processo de produção da decisão política.

Bradley (1980) aponta que a necessidade de estudos nessa área surgiu a partir da constatação de que os temas debatidos no âmbito do parlamento se mostravam cada vez mais técnicos e complexos, exigindo respostas institucionais a exemplo da ampliação do quadro de analistas legislativos e do aprofundamento da utilização de sistemas informatizados. $\mathrm{O}$ autor aplicou um survey junto legisladores do estado de Nevada que permitiu mapear as seguintes fontes 
de informação: audiências públicas nas comissões; palestras e fóruns; informações oriundas de agências federais; debates em plenário; relatórios preparados por analistas legislativos; organizações multilaterais e grupos de interesse; professores e pesquisadores universitários; bibliotecas; conhecimento próprio sobre o assunto; e, claro, informações obtidas a partir do que é elaborado pelas instituições da comunicação de massa, a exemplo dos jornais impressos.

Também está na pauta de preocupações destes estudos a tentativa de compreender quais destas fontes de informação são privilegiadas pelos parlamentares (e por qual motivo o são). O próprio Bradley (1980) conclui que as audiências nas comissões colaboram para mensurar os custos de implementar determinada alternativa; já considerar o que dizem organizações da sociedade civil permite entender reivindicações que poderiam não estar no horizonte da discussão levada adiante por atores estatais (ZWEIR, 1979). Já O'Reilly (1982) analisa em que medida fontes de informação percebidas como sendo de maior qualidade são mais comumente acionadas.

Mesmo que privilegiar determinadas fontes de informação possa estar associado à decisão política que o parlamentar toma, não necessariamente há uma relação de determinação.

Os trabalhos mais recentes, a exemplo do estudo de Orton, Marcella e Baxter (2000) sobre parlamentares do Reino Unido, ressaltam a importância de fontes formais e informais de dados, bem como destacam a importância de assessores. Outra preocupação desses mesmos investigadores é concernente aos efeitos do ambiente de comunicação digital sobre o repertório dominado pelos representantes.

Neste artigo, a ideia é verificar, de modo mais específico, o uso das plataformas midiáticas não somente na condição de fontes de informação, mas, também, em que medida os agentes dizem nelas confiar e quais eles consideram mais pertinentes para uma configuração favorável de suas imagens públicas.

Assim sendo, por estarem atentos à ideia de campanha permanente (COOK, 2002; ORNSTEIN; MANN, 2000; MCNAIR, 2016), os agentes do campo político demonstram preocupação constante em empregar uma variedade de ferramentas de comunicação a fim de construir uma imagem pública que lhes seja favorável. Autores como Rubim (2004) e Dias (2013) apontam que, ao longo do século XX, as plataformas de comunicação de massa passaram a exercer um papel singular em disputas que englobam grandes contingentes de eleitores, exigindo dos candidatos adaptações discursivas. Nesse sentido, ampliam-se sobre os representantes as pressões para que obtenham literacia a fim de elaborar mensagens de acordo com a gramática adequada à audiência típica de cada suporte de comunicação (FARRELL, 1998; MAAREK, 2008).

É por conta de tais práticas que parcela relevante dos pesquisadores na área de Comunicação e de Ciência Política tem chamado a atenção para conceitos a exemplo de 
"democracia de audiência" (MANIN, 1997) ou de "midiatização" (STRÖMBACK, 2008; ELMELUND-PRÆSTEKÆR et al., 2011). Tais conceitos implicam considerar os media como agentes políticos com capacidade de influenciar tanto a formação de imagens coletivamente compartilhadas, como aquilo que está nos bastidores da cena política visível ao público. Ademais, firma-se como tendência, em diferentes regimes democráticos contemporâneos, a ideia de “personalização da política” (BRAGA; BECHER, 2012; VAN AELST et al., 2012; SCAMMELL, 2016), segundo a qual o próprio agente político procura se tornar o centro da visibilidade em detrimento de instituições tradicionais (como os partidos).

Argumenta-se, porém que a literatura nacional ainda se mostra escassa no que concerne a um panorama voltado a identificar em que medida os agentes do campo político consomem e confiam nas instituições da comunicação; também há poucos estudos acerca dos modos como os eleitos avaliam a eficácia dos media no que se refere à autopromoção. Adotar tal perspectiva com uma visada que privilegie a comunicação regional é algo ainda mais raro.

Sabe-se, por exemplo, que o tipo de relação que o agente político mantém com seu eleitorado, bem como o cargo ocupado pelo representante, influenciam os modos de adoção das plataformas midiáticas. Uma campanha para vereador que tem como base eleitoral determinado bairro no qual os habitantes têm baixa renda pode, talvez (já que renda não é o único fator a influenciar a decisão de voto, conforme Figueiredo (2008), demandar maior investimento no chamado "corpo a corpo", em detrimento do uso de comunicação online (MARQUES e MONT'ALVERNE, 2016; HERMAN, 2017). Ou seja, as ferramentas empregadas em campanhas eleitorais precisam ser condizentes com o perfil do público e da região que o candidato procura atingir.

É esse tipo de abordagem individual que os representantes conferem à comunicação que carece de investigação empírica que envolva, dentre outras técnicas, a aplicação de survey. Para dar conta de tal desafio, a primeira dimensão desse trabalho trata do consumo de informações através de diferentes empresas jornalísticas. Entre os parlamentares federais, segundo a pesquisa Mídia e Política (FSB COMUNICAÇÕES, 2016), as principais fontes de informação são os jornais e a internet e suas instituições jornalísticas preferidas são a Folha de S. Paulo e $O$ Estado de $S$. Paulo. Quando perguntados sobre quais jornais costumam ler, $89 \%$ afirmam que leem a Folha e 75\% afirmam ler jornais locais de sua região. O Estadão fica em terceiro lugar, com $74 \%$ das respostas.

A segunda dimensão aqui analisada refere-se à confiança dos parlamentares entrevistados em diferentes plataformas midiáticas. Sabe-se que há grande desconfiança dos cidadãos em relação à veracidade dos conteúdos veiculados pelos media. Segundo Gomes (2016), a explicação da 
sensação de parcialidade do Jornalismo pode não estar relacionada apenas às empresas jornalísticas, mas também às características de quem as lê. Para Gunther (2015), o efeito de mídia hostil encontra terrenos mais férteis em períodos eleitorais e indivíduos de perfil partidarizado. Turcotte, et. al (2015) indicam que, nas últimas décadas, os públicos teriam se tornado menos atentos a notícias mainstream e haveria um declínio constante da confiança pública nas instituições de notícias.

No Brasil, de acordo com a Pesquisa Brasileira de Mídia de 2015, 18\% dos entrevistados afirmaram sempre confiar em notícias de jornais, enquanto $15 \%$ privilegiam notícias do rádio, $17 \%$ confiam em notícias da TV, $11 \%$ em notícias de revistas e apenas 5\% em notícias das redes sociais. Outros 5\% afirmam nunca confiar nos jornais e 20\% disseram nunca confiar nas redes sociais. Segundo a Pesquisa Mídia e Política (FSB COMUNICAÇÕES, 2016), 70\% dos parlamentares nacionais confiam nas notícias veiculadas por jornais, $60 \%$ confiam em notícias do rádio e da TV e apenas $19 \%$ e $18 \%$ confiam em notícias veiculadas no Twitter e no Facebook, respectivamente.

A terceira dimensão deste trabalho refere-se à opinião dos parlamentares acerca da eficiência dos media para sua autopromoção política, sendo perceptível o destaque que a literatura confere às plataformas midiáticas digitais (ENLI e SKOGERBØ, 2013). Cervi et al. (2011) argumentam que, em comparação com os meios de comunicação "tradicionais", a internet, como veículo de informação e comunicação, vem se tornando um espaço propício para uma maior aproximação entre os agentes políticos, líderes de opinião, militantes e o eleitorado de modo geral. Contudo, deve-se ponderar que nem sempre essa larga visibilidade possibilitada pela comunicação digital chega a ser vantajosa, uma vez que as mensagens difundidas por esse meio podem chegar descontextualizadas e, consequentemente, serem mal interpretadas pelos receptores (STROMERGALLEY, 2000; MARQUES et al., 2014). Todavia, ainda assim as redes sociais da internet têm se destacado como recurso para a autopromoção da imagem de políticos (MARQUES et al., 2014).

\section{HIPÓTESES E METODOLOGIA}

As hipóteses a seguir foram elaboradas em sintonia com as três dimensões de estudo aqui consideradas: (a) os hábitos de consumo; (b) a confiança atribuída aos media por parte de agentes do Poder Legislativo; e (c) o grau de eficiência que os deputados conferem a diferentes plataformas midiáticas com vistas à autopromoção política.

Hipótese 1) Uma vez que os deputados têm interesse em alcançar um público de âmbito regional, a maioria deles tende a acompanhar a cobertura realizada por jornais locais e estaduais.

Tendo em vista o conceito de campanha permanente, já mencionado acima, é plausível a ideia de que os parlamentares estaduais estão mais atentos à cobertura jornalística realizada por 
jornais locais e estaduais com o intuito de acompanhar o noticiário e a construção de suas imagens públicas. Além disso, espera-se que os resultados aqui analisados sejam condizentes com os dados da pesquisa Mídia e Política, realizada pela FSB COMUNICAÇÕES (2016), que aponta que 75\% dos parlamentares federais afirmam ler jornais locais de sua região.

Hipótese 2) A confiança dos parlamentares acerca de diferentes plataformas midiáticas enquanto fontes de informações varia conforme o perfil pessoal e político de cada deputado idade, gênero, grau de instrução, número de legislaturas na ALEP e orientação ideológica do partido.

Tomando como base a Pesquisa Brasileira de Mídia de 2015, que aponta variações na confiança dos brasileiros em diferentes plataformas midiáticas, espera-se que essas variações também ocorram entre os parlamentares entrevistados. De acordo com a pesquisa, mulheres, pessoas de idade mais avançada e com menor grau de escolaridade confiam mais na TV do que os respondentes homens, mais jovens e com maior grau de educação formal. O rádio, por sua vez, mostra-se mais confiável para homens mais velhos e com maior escolaridade. Para os jornais e revistas impressos, as variações são menores entre o perfil dos respondentes. As redes sociais, consideradas confiáveis por apenas $5 \%$ dos brasileiros, têm maior confiabilidade entre indivíduos mais jovens e com maior escolaridade.

Hipótese 3) As ferramentas de comunicação consideradas mais eficientes pelos parlamentares para autopromoção política são as redes sociais digitais, principalmente entre os deputados que possuem o seguinte perfil: jovens, maior grau de escolaridade, menor número de legislaturas e pertencentes a partidos mais à esquerda.

Essa hipótese é embasada pelo argumento de Marques et al. (2014). Ao tratarem da adoção do Twitter como ferramenta de comunicação por integrantes da Câmara dos Deputados, os autores concluem que $(i)$ parlamentares mais jovens possuem maior taxa de tweets publicados e maior número de seguidores; (ii) deputados que estão na primeira legislatura postam mais mensagens e (iii) parlamentares considerados mais de esquerda tendem a tuitar mais e a terem mais seguidores (MARQUES et al., 2014). Apesar de a pesquisa referenciada ter como foco a rede social Twitter, essa abordagem pode ser expandida para as demais redes sociais, ao considerá-las como espaço de debate e visibilidade da imagem dos representantes políticos.

O presente estudo emprega metodologia quantitativa para averiguar as três hipóteses. Foi aplicado um survey presencial nos gabinetes de 52 dos 54 parlamentares que exerciam mandato na Assembleia Legislativa do Paraná (ALEP).

A elaboração dos questionários implicou a realização de dois pré-testes, voltados a aperfeiçoar o teor das questões elaboradas. O survey, composto por 17 questões com opções de 
respostas estimuladas, divide-se em duas dimensões; $(i)$ os hábitos de consumo midiático por parte dos parlamentares, e (ii) o uso estratégico das plataformas midiáticas para a promoção política.

Dentre os 54 parlamentares que exerciam mandato entre maio e junho de 2016 na ALEP apenas dois deputados não responderam às solicitações dos investigadores, sendo que, 41 responderam pessoalmente ao survey e 11 delegaram suas respostas a seus assessores.

\section{Quadro 1 - Deputados que responderam ao survey ${ }^{6}$ :}

\begin{tabular}{|l|l|}
\hline Deputado Estadual & Partido \\
\hline Pedro Lupion* & DEM \\
\hline Plauto Miró* & DEM \\
\hline Missionário Ricardo Arruda & DEM \\
\hline Elio Rusch* & DEM \\
\hline Nelson Justus* & DEM \\
\hline Nelson Luersen & PDT \\
\hline Marcio Pauliki* & PDT \\
\hline Scanavaca & PDT \\
\hline Requião Filho & PMDB \\
\hline Anibelli Neto & PMDB \\
\hline Nereu Moura* & PMDB \\
\hline Ademir Bier & PMDB \\
\hline Maria Victória & PP \\
\hline Schiavinato & PP \\
\hline Marcio Pacheco & PPL \\
\hline Cristina Silvestri & PPS \\
\hline Tercílio Turini & PPS \\
\hline Pastor Edson Praczyk & PRB \\
\hline Gilberto Ribeiro & PRB \\
\hline Alexandre Curi* & PSB \\
\hline Tiago Amaral* & PSB \\
\hline Stephanes Junior & PSB \\
\hline Jonas Guimarães & PSB \\
\hline Romanelli & PSB \\
\hline Claudia Pereira & PSC \\
\hline Evando Araújo & PSC \\
\hline Paranhos* & PSC \\
\hline Gilson de Souza & PSC \\
\hline Palozi & PSC \\
\hline Wilmar Reichembach & PSC \\
\hline Ney Leprevost & PSD \\
\hline Guto Silva & PSD \\
\hline Cobra Repórter & PSD \\
\hline & \\
\hline
\end{tabular}

${ }^{6}$ Após várias tentativas, nem os deputados Dr. Batista (PMN) e Luiz Carlos Martins (PSD), nem seus assessores se disponibilizaram a responder ao survey. 


\begin{tabular}{|l|l|}
\hline Chico Brasileiro & PSD \\
\hline Marcio Nunes & PSD \\
\hline Hussein Barki & PSD \\
\hline Paulo Litro & PSDB \\
\hline Bernardo Carli & PSDB \\
\hline Evandro Junior & PSDB \\
\hline André Bueno & PSDB \\
\hline Alexandre Guimarães* & PSDB \\
\hline Cantora Mara Lima* & PSDB \\
\hline Mauro Morais & PSDB \\
\hline Francisco Buhrer & PSDB \\
\hline Ademar Traiano & PSDB \\
\hline Adelino Ribeiro & PSL \\
\hline Professor Lemos & PT \\
\hline Péricles de Mello & PT \\
\hline Tadeu Veneri & PT \\
\hline Tião Medeiros & PTB \\
\hline Rasca Rodrigues & PV \\
\hline Felipe Francischini & SD \\
\hline
\end{tabular}

* Survey respondido pelo(a) assessor(a) de comunicação do(a) deputado(a) ${ }^{7}$.

Fonte: Elaboração própria (2018).

As variáveis dependentes aqui analisadas são: (a) instituições jornalísticas consumidas pelos parlamentares, (b) confiança atribuída aos media pelos parlamentares, e (c) grau de eficiência que os deputados atribuem a diferentes plataformas midiáticas com vistas à autopromoção política. As variáveis independentes consistem em: (d) idade do parlamentar, (e) gênero, (f) grau de instrução, (g) número de legislaturas na ALEP, (h) posicionamento ideológico do partido.

Para dar conta das hipóteses, são apresentadas distribuições de frequências e os resultados de Gama ou do Coeficiente de Contingência - testes que determinam o grau de associação entre variáveis categóricas (importante enfatizar que não são apresentados os testes de significância estatística porque o corpus desse trabalho é referente à população e não a uma amostra). Enquanto o Gama é utilizado para variáveis ordinais, o Coeficiente de Contingência é utilizado para variáveis nominais. Quando o resultado fica abaixo de 0,4 a associação é considerada baixa; se o resultado fica no intervalo de 0,4 a 0,6, existe uma associação moderada entre as variáveis; o resultado acima de 0,6 indica alta associação (FIELD, 2005).

\footnotetext{
${ }^{7}$ Nesses casos, apenas os assessores estavam disponíveis para responder ao survey. Suas respostas, conforme declaração deles próprios, são condizentes com os hábitos e opiniões dos parlamentares aos quais representavam.
} 


\section{ANÁLISE DOS DADOS}

Neste tópico, são apresentados os dados sobre os hábitos de consumo e sobre a confiança atribuída aos media por parte de agentes do Poder Legislativo. Também são detalhados os dados atinentes às plataformas midiáticas que os deputados consideram mais eficientes para a autopromoção política. Ao final, discutem-se os achados do levantamento, em conexão com a literatura.

\section{Hábitos de Consumo de Informações por Parte dos Deputados Estaduais}

Esta subseção se debruça sobre os hábitos de consumo de informação por parte dos parlamentares. A Tabela 1 revela os hábitos de leitura dos deputados estaduais considerando os principais jornais e revistas brasileiros. Nesta questão do survey, o entrevistado poderia indicar mais de uma instituição jornalística, não havendo um limite de opções. É importante destacar que a opção foi por não diferenciar jornais impressos e jornais online (e nem revistas impressas de revistas online), visto que a intenção aqui era de comparar o consumo de diferentes empresas jornalísticas, e não de diferentes plataformas midiáticas. Portanto, quando o parlamentar afirma se informar através da Folha de S. Paulo, por exemplo, considera-se tanto o jornal impresso quando o jornal online.

Tabela 1 - Instituições jornalísticas por meio das quais os parlamentares afirmam ter o hábito de obter informações ${ }^{8}$

\begin{tabular}{lc}
\hline Instituições jornalísticas & $\begin{array}{c}\text { Porcentagem de deputados que } \\
\text { afirmam se informar pela } \\
\text { instituição jornalística }\end{array}$ \\
\hline Gazeta do Povo $^{9}$ & $96,1 \%(49)$ \\
\hline Folha de S. Paulo & $92,2 \%(47)$ \\
\hline Veja & $70,6 \%(36)$ \\
\hline O Estado de S. Paulo & $52,9 \%(27)$ \\
\hline Época & $35,3 \%(18)$ \\
\hline
\end{tabular}

${ }^{8}$ Resposta semiestimulada à seguinte questão: "Para cada um dos jornais e revistas que vou citar, responda se o (a) senhor (a) lê ou não: 1. Gazeta do Povo, 2. Folha de S. Paulo, 3. O Globo, 4. Tribuna do Paraná, 5. O Estado de S. Paulo, 6. Veja, 7. Época, 8. Isto é, 9. Carta Capital, 10. Outro. Qual?, 98. NS, 99. NR”.

${ }^{9}$ No momento da aplicação do survey, a Gazeta do Povo ainda possuía versão impressa. Atualmente, o jornal diário está disponível apenas em plataforma digital. 


\begin{tabular}{ll}
\hline Isto é & $35,3 \%(18)$ \\
\hline O Globo & $35,3 \%(18)$ \\
\hline Carta Capital & $27,5 \%(14)$ \\
\hline Tribuna do Paraná & $21,6 \%(11)$ \\
\hline
\end{tabular}

Fonte: Elaboração própria (2018)

Verificou-se que o jornal Gazeta do Povo é o mais lido pelos deputados estaduais do Paraná. Além disso, quando indagados sobre se havia outro jornal ou revista que também consideravam importante do ponto de vista do consumo de informações, 21 dos parlamentares entrevistados (quase metade deles) indicaram outros jornais estaduais e locais, como por exemplo, o Bem Paraná (de alcance estadual), a Folha de Londrina (com circulação mais evidente no referido município) e o Diário dos Campos (Ponta Grossa e demais municípios da região dos Campos Gerais).

Nota-se também que os jornais Folha de S. Paulo e $O$ Estado de S. Paulo são frequentemente mencionados pelos representantes, tendo sido indicados por 92,2\% e 52,9\% dos entrevistados, respectivamente. Segundo a pesquisa Mídia e Política (FSB COMUNICAÇÕES, 2016), a Folha é o jornal de preferência de 65\% dos deputados federais e o Estado de S. Paulo fica em segundo lugar, com $41 \%$. Além disso, $75 \%$ dos parlamentares nacionais afirmam ler jornais locais de suas regiões. Portanto, os hábitos de leitura dos deputados estaduais paranaenses são condizentes com os hábitos dos representantes no legislativo nacional.

\section{Confiança dos Parlamentares em Diferentes Plataformas Midiáticas para Consumo de Informações}

Nesta subseção, são apresentados os dados sobre confiança dos parlamentares em diferentes plataformas midiáticas, providenciando-se um cruzamento dessas informações com as variáveis independentes: idade, gênero, grau de instrução, número de legislaturas na ALEP e identificação ideológica do partido ao qual o deputado é filiado.

Cada entrevistado foi orientado a indicar apenas uma "mídia" como aquela que apresenta informações mais confiáveis, estando disponíveis as seguintes opções: televisão; rádio; jornais (versão impressa e online); revistas (versão impressa e online); e redes sociais. 
Tabela 2 - Confiança dos parlamentares nas plataformas midiáticas ${ }^{10}$

\begin{tabular}{cc}
\hline Plataformas midiáticas & $\begin{array}{c}\text { Porcentagem de deputados que afirmam } \\
\text { confiar na plataforma midiática }\end{array}$ \\
\hline Jornais & $38,3 \%(18)$ \\
\hline Televisão & $31,9 \%(15)$ \\
\hline Redes sociais digitais & $14,9 \%(7)$ \\
\hline Rádio & $12,8 \%(6)$ \\
\hline Revistas & $2,1 \%(1)$ \\
\hline Total & $100 \%(47)^{11}$ \\
\hline
\end{tabular}

Fonte: Elaboração própria (2018)

A Tabela 2 mostra que os jornais e a televisão são as plataformas midiáticas consideradas mais confiáveis pelos parlamentares. As redes sociais, por sua vez, são indicadas como mais confiáveis apenas por sete dos respondentes.

O Quadro 2, mais abaixo, expõe os resultados de Gama/Coeficiente de Contingência dos cruzamentos entre a confiança dos parlamentares em diferentes plataformas midiáticas (variável dependente) e o perfil político e pessoal do parlamentar - idade, gênero, grau de instrução, número de legislaturas na ALEP e identificação ideológica do partido (variáveis independentes). Nota-se alto grau de associação apenas entre confiança em plataformas midiáticas e grau de instrução, já que o resultado do teste de Gama é de 0,633. Não há associação entre as demais variáveis, já que os testes desses cruzamentos ficaram abaixo de 0,4 .

Quadro 2 - Gama/Coeficiente de Contingência entre confiança dos parlamentares nas plataformas midiáticas e perfil pessoal/político do parlamentar

\begin{tabular}{lccccc}
\hline & Idade & Gênero & $\begin{array}{c}\text { Grau de } \\
\text { instrução }\end{array}$ & $\begin{array}{c}\text { Número de } \\
\text { legislaturas na } \\
\text { ALEP }\end{array}$ & $\begin{array}{c}\text { Identificação } \\
\text { ideológica do } \\
\text { partido }\end{array}$ \\
\hline $\begin{array}{l}\text { Confiança em } \\
\text { diferentes }\end{array}$ & 0,163 & 0,330 & $0,633^{*}$ & $-0,010$ & 0,115 \\
\hline
\end{tabular}

\footnotetext{
${ }^{10}$ Resposta estimulada à seguinte questão: "Dentre as seguintes mídias que compõem o disco, em qual o (a) senhor (a) mais confia na veracidade das informações? 1.Televisão, 2. Rádio, 3. Jornal, 4. Revista, 5. Redes sociais da internet, 98. NS, 99. NR".

${ }^{11}$ Cinco deputados não responderam a essa questão.
} 


\section{plataformas}

\section{midiáticas}

* Há associação alta entre as variáveis.

Fonte: Elaboração própria (2018)

A Tabela 3 apresenta as frequências cruzadas entre a confiança dos parlamentares nas informações veiculadas por meio de diferentes mídias (variável dependente) e seu grau de instrução (variável independente).

Tabela 3 - Confiança nas informações veiculadas pelas plataformas midiáticas $\mathbf{x}$ grau de instrução dos deputados

\begin{tabular}{ccccc}
\hline Plataforma & $\begin{array}{c}\text { Médio } \\
\text { completo }\end{array}$ & $\begin{array}{c}\text { Superior } \\
\text { incompleto }\end{array}$ & $\begin{array}{c}\text { Superior } \\
\text { completo }\end{array}$ & Total \\
\hline Televisão & $80 \%(4)$ & $25 \%(1)$ & $26,3 \%(10)$ & $31,9 \%(15)$ \\
Rádio & $20 \%(1)$ & $25 \%(1)$ & $10,5 \%(4)$ & $12,8 \%(6)$ \\
Jornais & $0 \%$ & $50 \%(2)$ & $42,1 \%(16)$ & $38,3 \%(18)$ \\
Revistas & $0 \%$ & $0 \%$ & $2,6 \%(1)$ & $2,1 \%(1)$ \\
Redes Sociais & $0 \%$ & $0 \%$ & $18,4 \%(7)$ & $4,9 \%(7)$ \\
digitais & & & & $100 \%(47)$ \\
Total & $100 \%(5)$ & $100 \%(4)$ & $100 \%(38)$ & \\
\hline
\end{tabular}

Fonte: Elaboração própria (2018)

O valor de Gama $(0,633)$ indica que há alta associação entre as duas variáveis, ou seja, (a) confiança dos parlamentares na televisão, rádio, jornais, revistas e redes sociais da internet varia de acordo com (b) seu grau de instrução. Enquanto para os parlamentares com ensino médio completo a televisão é considerada mais confiável (80\%), os com acesso ao ensino superior confiam mais em jornais: com 50\% (aqueles com superior incompleto) e 42,1\% (com superior completo). As redes sociais, por sua vez, foram indicadas como mais confiáveis apenas por sete parlamentares - todos eles com ensino superior completo. As revistas ocupam o último lugar, sendo indicadas como mais confiáveis somente por um parlamentar - com superior completo. Percebe-se, porém, que dez dos parlamentares com superior completo ainda indicam a televisão como plataforma jornalística mais confiável.

Nota-se também que, entre os 52 deputados entrevistados, 78,8\% possuem ensino superior completo e 7,7\% possuem ensino superior incompleto. Esse quadro condiz com os dados sobre o 
grau de instrução dos deputados federais da atual legislatura, já que $80 \%$ deles possuem ensino superior completo (REIS, 2014).

\section{Plataformas Consideradas Mais Eficientes para a Autopromoção Política}

Os parlamentares que responderam ao survey foram orientados a atribuir diferentes graus de eficiência às plataformas midiáticas no que se refere à autopromoção política. Os entrevistados tiveram de indicar uma opção dentre as disponíveis (nada eficiente, pouco eficiente, eficiente ou nada eficiente) para avaliar a eficácia de cada plataforma.

\section{Tabela 4 - Opinião dos parlamentares acerca da eficiência dos media para a autopromoção política}

\begin{tabular}{lccccc}
\hline \multicolumn{1}{c}{ Plataforma } & $\begin{array}{c}\text { Nada } \\
\text { eficiente }\end{array}$ & $\begin{array}{c}\text { Pouco } \\
\text { eficiente }\end{array}$ & Eficiente & Muito eficiente & Total \\
\hline Televisão & $1,9 \%(1)$ & $13,5 \%(7)$ & $32,7 \%(17)$ & $51,9 \%(27)$ & $100 \%(52)$ \\
\hline Rádio & $0 \%$ & $11,6 \%(6)$ & $44,4 \%(23)$ & $44,4 \%(23)$ & $100 \%(52)$ \\
\hline $\begin{array}{l}\text { Jornais } \\
\text { estaduais/ } \\
\text { nacionais }\end{array}$ & $7,7 \%(4)$ & $38,5 \%(20)$ & $50 \%(26)$ & $3,8(2)$ & $100 \%(52)$ \\
\hline $\begin{array}{l}\text { Jornais locais } \\
\text { Redes sociais } \\
\text { digitais }\end{array}$ & $3,8 \%(2)$ & $21,2 \%(11)$ & $51,9 \%(27)$ & $23,1 \%(12)$ & $100 \%(52)$ \\
\hline $\begin{array}{l}\text { Fonte: Elaboração própria (2018) } \\
\text { n }\end{array}$ & $1,9 \%(1)$ & $30,8 \%(16)$ & $67,3 \%(35)$ & $100 \%(52)$ \\
\end{tabular}

$\mathrm{Na}$ Tabela 4, vê-se que os deputados estaduais paranaenses consideram as redes sociais mais eficientes para a sua própria promoção política. Dos 52 entrevistados, apenas um marcou esse tipo de mídia como pouco eficiente. Quando indagados sobre as redes sociais que mais utilizam para autopromoção, 98,1\% identificaram o Facebook em primeiro lugar.

A televisão é considerada eficiente para promoção política por $51,9 \%$ dos parlamentares. Em relação ao rádio, 23 respondentes o consideram muito eficiente e outros 23 o indicam como eficiente para a promoção política. Os jornais estaduais e nacionais e os jornais locais, por sua vez, são considerados eficientes por $50 \%$ e $51,9 \%$ dos entrevistados, respectivamente.

\footnotetext{
12 Aqui, novamente, as versões on-line e impressas de jornais estaduais ou nacionais e de jornais locais não foram diferenciadas.
} 
Nota-se que a resposta "nada eficiente" foi pouco acionada pelos respondentes. No caso do rádio e das redes sociais digitais, nenhum parlamentar afirmou que essas mídias são ineficientes para a autopromoção política. Esse resultado implica que, para os deputados estaduais, a mínima visibilidade obtida por meio de qualquer uma das plataformas midiáticas citadas representa possibilidade de promoção de sua imagem pública.

A seguir, são apresentados os cruzamentos entre as variáveis: opinião dos parlamentares acerca da eficiência das redes sociais digitais para a autopromoção política, de um lado, e idade, grau de instrução, número de legislaturas na ALEP e identificação ideológica do partido, de outro. O Quadro 3 apresenta os valores de Gama entre as variáveis.

\section{Quadro 3 - Resultados de Gama para opinião dos parlamentares acerca da} eficiência das redes sociais digitais para a promoção política e seu perfil pessoal/político

\begin{tabular}{|l|c|c|c|c|}
\hline & Idade & $\begin{array}{c}\text { Grau de } \\
\text { instrução }\end{array}$ & $\begin{array}{c}\text { Número de } \\
\text { legislaturas na } \\
\text { ALEP }\end{array}$ & $\begin{array}{c}\text { Identificação } \\
\text { ideológica do } \\
\text { partido }\end{array}$ \\
\hline $\begin{array}{l}\text { Opinião acerca da } \\
\text { eficiência das redes } \\
\text { sociais digitais }\end{array}$ & $-0,421^{*}$ & $-0,106$ & 0,057 & 0,256 \\
\hline
\end{tabular}

* Há associação moderada entre variáveis.

Fonte: Elaboração própria (2018)

Verifica-se, a partir do Quadro 3, que existe associação apenas entre (a) eficiência atribuída às redes sociais digitais para a autopromoção política e (b) idade. O valor de Gama $(-0,421)$ demonstra que há dependência negativa e moderada entre as variáveis. Isso quer dizer que, à medida que a idade do parlamentar aumenta, a avaliação de que as redes sociais são muito eficientes tende a se reduzir. A Tabela 5 detalha os resultados desse cruzamento.

Tabela 5 - Opinião dos parlamentares acerca da eficiência das redes sociais digitais para a autopromoção política $x$ idade do parlamentar

\begin{tabular}{llllll}
\hline $\begin{array}{l}\text { Grau de } \\
\text { eficiência }\end{array}$ & Até 40 anos & $\begin{array}{l}\text { De 41 e 50 } \\
\text { anos }\end{array}$ & $\begin{array}{l}\text { De 51 a 59 } \\
\text { anos }\end{array}$ & $\begin{array}{l}\text { 60 anos ou } \\
\text { mais }\end{array}$ & Total \\
\hline Nada eficiente & $0 \%$ & $0 \%$ & $0 \%$ & $0 \%$ & $0 \%$ \\
\hline Pouco eficiente & $7,7 \%(1)$ & $0 \%$ & $0 \%$ & $0 \%$ & $1,9 \%(1)$ \\
\hline Eficiente & $7,7 \%(1)$ & $30,8 \%(4)$ & $26,7 \%(4)$ & $63,6 \%(7)$ & $30,8 \%(16)$ \\
\hline Muito eficiente & $84,6 \%(11)$ & $69,2 \%(9)$ & $63,6 \% \%(7)$ & $36,4 \%(4)$ & $67,3 \%(35)$ \\
\hline Total & $100 \%(13)$ & $100 \%(13)$ & $100 \%(15)$ & $100 \%(11)$ & $100 \%(52)$ \\
\hline
\end{tabular}


Gama $=-0,421$

Fonte: Elaboração própria (2018)

A maioria dos parlamentares, independentemente da idade, considera as redes sociais eficientes ou muito eficientes para a autopromoção política. Entretanto, verifica-se que, entre os deputados mais velhos, existe uma tendência de redução da resposta "muito eficiente". Considerando os parlamentares com até 40 anos, onze afirmam que as redes sociais são muito eficientes. Apenas um deputado com menos de 40 anos, considera-as pouco eficientes para a autopromoção política. Já entre os deputados de 41 a 50 anos, nove consideram as redes sociais muito eficientes. O número fica em sete entre deputados com 51 a 59 anos e em quatro entre deputados com mais de 60 anos.

\section{Discussão dos Resultados e Conclusão}

Os objetivos deste artigo foram (a) investigar quais instituições jornalísticas são mais utilizadas por parlamentares com a finalidade de consumir informações, (b) verificar o grau de confiança que eles depositam em diferentes plataformas e, por fim, (c) examinar o grau de eficiência que os representantes atribuem a diferentes plataformas midiáticas com vistas à autopromoção. Para isso foram propostas três hipóteses.

De acordo com a H1, a maioria dos parlamentares tende a acompanhar a cobertura realizada por jornais locais e estaduais. Essa hipótese é confirmada, pois, uma vez que se interessam em alcançar um público de âmbito estadual, os deputados seguem mais de perto a cobertura realizada por empresas jornalísticas que atuam no próprio estado. Apenas três dos 52 parlamentares entrevistados não indicaram serem leitores do jornal Gazeta do Povo. Além disso, 21 parlamentares (quase metade dos entrevistados) afirmaram que se informam através de outros jornais estaduais ou locais, como o Bem Paraná, a Folha de Londrina e o Diário dos Campos. Esse resultado demonstra que os parlamentares estão atentos às notícias de domínio local - resultado semelhante ao que foi encontrado quando o foco da investigação são os parlamentares federais, como indica a pesquisa Mídia e Política (FSB COMUNICAÇÕES, 2016).

Nesse sentido, percebe-se que, além de obterem informações a partir de jornais locais e estaduais, os hábitos de leitura dos parlamentares entrevistados refletem os hábitos da população brasileira, já que os jornais $O$ Estado de S. Paulo e a Folha de S. Paulo estão entre os mais lidos do país (PODER360, 2017; ANJ, 2017). Ademais, os resultados se assemelham, também, aos hábitos de leitura dos parlamentares nacionais, que indicam a Folha e o Estadão como veículos 
preferidos - além de $75 \%$ deles afirmarem que leem jornais locais de suas regiões (FSB COMUNICAÇÕES, 2016).

A H2 sugeriu que a confiança dos parlamentares em diferentes plataformas midiáticas varia conforme o perfil pessoal e político de cada deputado. Essa hipótese é parcialmente confirmada, já que os dados demonstram que sua confiança nos media tem alta associação com o grau de instrução dos representantes na Assembleia e baixa associação com as demais variáveis independentes. $\mathrm{Ou}$ seja, os deputados que possuem somente o ensino médio completo dizem confiar mais nas informações veiculadas pela televisão, enquanto os parlamentares com ensino superior (completo ou não) afirmam confiar mais em jornais.

A H3 também foi parcialmente confirmada. Essa hipótese dava conta de que as ferramentas de comunicação consideradas mais eficientes pelos parlamentares para autopromoção política seriam as redes sociais digitais, principalmente entre os deputados mais jovens, com maior grau de escolaridade, menor número de legislaturas e pertencentes a partidos mais à esquerda. Apenas um dos 52 entrevistados indicou que as redes sociais digitais são pouco eficientes para a autopromoção política, enquanto 16 parlamentares as consideraram eficientes e outros 35 disseram que elas são muito eficientes. Entretanto, o resultado de Gama demonstra que há associação moderada e negativa apenas entre idade e as opiniões sobre redes sociais. Isto é, à medida que aumenta a idade do parlamentar, diminui sua tendência em considerar essa plataforma midiática como muito eficiente para a autopromoção política. Entre os mais velhos, a resposta predominante a essa questão é "eficiente", e não "muito eficiente".

De forma geral, ao visualizar as três dimensões de dados aqui trabalhadas (os hábitos de consumo; a confiança atribuída aos media; e as opiniões dos agentes do Poder Legislativo acerca da eficiência de diferentes plataformas midiáticas para a autopromoção política), percebe-se que os parlamentares envolvidos na pesquisa, ao mesmo tempo em que confiam pouco na veracidade das informações veiculadas pelas redes sociais, consideram essas plataformas eficientes ou muito eficientes quando se trata da projeção de suas imagens. No caso, isso implica que os representantes sabem que os cidadãos/eleitores estão no ambiente de comunicação digital e que precisam chegar a esse público, ainda que os deputados resistam a se informar por meio das conexões estabelecidas em redes sociais da internet. Aqui, uma vez mais, testemunha-se que os hábitos dos deputados paranaenses são condizentes com os hábitos de mídia dos cidadãos brasileiros, já que, segundo a Pesquisa Brasileira de Mídia de 2016, "a maioria dos usuários de internet confia poucas vezes ou nunca confia nas notícias de sites, de blogs e de redes sociais" (BRASIL, 2016, p. 33).

Percebe-se, ademais, que não são as mesmas as variáveis independentes associadas, de um lado, com a confiança dos parlamentares nos media e, de outro, com suas opiniões acerca da 
eficiência das redes sociais digitais para a autopromoção política. Enquanto na primeira dimensão dos dados (confiança dos parlamentares nos media) apenas o grau de instrução mostra alta associação com a variável dependente, na segunda dimensão (opiniões acerca da eficiência das redes sociais digitais para a autopromoção política) somente a idade apresenta associação moderada com a variável dependente. Pode-se, então, reforçar o diagnóstico de que os hábitos de consumo de mídia pelos parlamentares não necessariamente são condizentes com as opiniões deles acerca dos media para a autopromoção política em um contexto de campanha permanente.

Antes de encerrar, é preciso reconhecer um conjunto de limitações da pesquisa ora apresentada. Em primeiro lugar, é verdade que este trabalho privilegia um estudo de alcance estadual, mas, não obstante, acredita-se que o texto pode colaborar no esforço para que sejam aprofundadas as investigações concernentes ao relacionamento que agentes do campo político mantêm com diferentes plataformas midiáticas - seja para consumo próprio de informações, seja para promoverem suas imagens públicas. Por último, sublinhe-se que em momentos de campanha eleitoral, as opiniões e comportamentos declarados pelos parlamentares podem se mostrar diferentes, assim como suas associações com as variáveis independentes aqui analisadas. Nesse sentido, novos empreendimentos de análise se mostram necessários para complementar as descobertas aqui reveladas.

\section{REFERÊNCIAS}

ASSOCIAÇÃO NACIONAL DE JORNAIS, Maiores Jornais do Brasil. BRASÍLIA, 2017. Disponível: http://www.anj.org.br/maiores-jornais-do-brasil. Acesso em: 23 set. 2017.

BENNETT, Lance. Communicating Global Activism. Information, Communication \& Society, v. 6, n. 2, p. 143-168, 2003.

BIMBER, Bruce. Information as a factor in congressional politics. Legislative Studies Quarterly, v. 16, n. 4 , p. 585-605, 1991.

BRADLEY, Raymond. Motivations in legislative information use. Legislative Studies Quarterly, v. 5, n. 3, p. 393-406, 1980.

BRAGA, Sérgio; BRECHER, André. Personalização da política e novas tecnologias. ENCONTRO ANUAL DA ANPOCS 2012, Caxambu, 2012. Anais [...]. Disponível em: https://www.anpocs.com/index.php/papers-36-encontro/gt-2/gt01-2/7835-personalizacao-dapolitica-e-novas-tecnologias-balanco-do-debate-e-evidencias-sobre-o-brasil/file. Acesso em: 23 set. 17.

CERVI, Emerson; MASSUCHIN, Michele. Novas mídias e eleições 2010: o uso do Twitter nas campanhas dos candidatos ao governo do Paraná. ENCONTRO DA ASSOCIAÇÃO 
BRASILEIRA DOS PESQUISADORES EM COMUNICAÇÃO E POLÍTICA, IV, 2011. Rio de Janeiro, 2011. Anais [...]. Disponível em: http://www.compolitica.org/home/wpcontent/uploads/2011/03/Emerson-Urizzi-Cervi-e-Michele-Goulart-Massuchin.pdf. Acesso em: 23 set. 17.

COLEMAN, Stephen. Westminster in the Information Age. In: COLEMAN, Stephen; TAYLOR, John; DONK, Wim van de (Ed.). Parliament in the Age of the Internet, Oxford University Press, 1999. p. 9-25.

COOK, Corey. The Contemporary Presidency. Presidential Studies Quarterly, v. 32, n. 4, p. 753-764, 2002.

DIAS, Marcia Ribeiro. Nas brumas do HGPE: a imagem partidária nas campanhas presidenciais brasileiras (1989 a 2010). Opinião Pública, Campinas, v. 19, n. 1, p. 198-219, 2013.

ELMELUND-PRASTEKAER, Christian; HOPMANN, David; NORGAARD, Asbjørn. Does Mediatization Change MP-Media Interaction and MP Attitudes toward the Media? Evidence from a Longitudinal Study of Danish MPs. International Journal of Press/Politics, v. 16, n. 3, p. 382403, 2011.

ENLI, Gunn; SKOGERB $\varnothing$, Eli. Personalized campaigns in party-centred politics: Twitter and Facebook as arenas for political communication. Information, Communication \& Society, v. 16, n. 5, p. 757-774, 2013.

FARRELL, David. M. Political consultancy overseas: The internationalization of campaign consultancy. Political Science \& Politics, v. 31, n. 2, p. 171-178, 1998.

FIELD, Andy. Discovering Statistics with SPSS. 3. ed. London: Sage, 2005.

FIGUEIREDO, Marcus. A decisão do voto. Belo Horizonte: Editora da UFMG, 2008.

FSB COMUNICAÇÕES. Deputados Federais, Mídia e Conjuntura Política. Relatório de pesquisa. Brasília: FSB Comunicações, 2016.

GOLBECK, Jennifer; GRIMES, Justin; ROGERS, Anthony. Twitter use by U.S. Congress. Journal of the American Society for Information Science and Technology, v. 61, n. 8, p.16121621,2010

GRAMACHO, Wladimir, JÁCOMO, André. Padrões de uso dos meios de comunicação no Brasil e seu impacto sobre níveis de informação política. Debates, Porto Alegre, v. 9, n. 3, p. 11-36, 2015.

GUNTHER, Albert. Hostile media perceptions. In: MAZZOLENI, Gianpietro. (Ed.) International Encyclopedia of Political Communication, London: John Wiley \& Sons Inc, 2016.

HERMAN, Fellipe. Campanhas Online e Sociabilidade Política: o uso do Facebook e Twitter por candidatos a vereador nas eleições de 2016 em Curitiba. 182 f. Dissertação (Mestrado em Ciência Política) - Universidade Federal do Paraná, Curitiba, 2017. 
LILLEKER, Darren; JACKSON, Nigel. Interacting, representing or just informing: Web 2.0 and UK MP? In: EUROPEAN CONSORTIUM FOR POLITICAL RESEARCH, GENERAL CONFERENCE. 5, Potsdam, 2009.

MAAREK, Philippe J.. Political marketing. John Wiley \& Sons, 2008.

MANIN, Bernard. Principles of Representative Government. Cambridge: Cambridge Press, 1997.

MARQUES, Francisco Paulo Jamil; MIOLA, Edna; AQUINO, Jakson Alves. Deputados brasileiros no Twitter: um estudo quantitativo dos padrões de adoção e uso da ferramenta. Revista Brasileira de Ciência Política, n. 14, p. 201-225, 2014.

MARQUES, Francisco Paulo Jamil; MONT'ALVERNE, Camila. How Important is Twitter to Local Elections in Brazil? A Case Study of Fortaleza City Council. Brazilian Political Science Review, v. 10, n. 3, p. 1-35, 2016.

McNAIR, Brian. Image, Political. In: MAZZOLENI, Gianpietro. (Ed.) International Encyclopedia of Political Communication, New Jersey: John Wiley \& Sons Inc, 2016.

MESQUITA, Nuno Coimbra; MOISÉS, José Álvaro; RICO, Bruno. As diferentes dinâmicas da corrupção: mídia, percepção e instituições no contexto brasileiro. In: CUNHA, Isabel Ferin; SERRANO, Estrela (Org). Cobertura jornalística da corrupção política: sistemas políticos, sistemas midiáticos, enquadramentos legais. Lisboa: Alethêia, 2014.

O'REILLY, Charles. Variations in decision makers' use of information sources: The impact of quality and accessibility of information. Academy of Management journal, v. 25, n. 4, p. 756$771,1982$.

ORTON, Robert; MARCELLA, Rita; BAXTER, Graeme. An observational study of the information seeking behaviour of Members of Parliament in the United Kingdom. In: Aslib Proceedings, p. 207-217, 2000.

PODER360, Jornais e Revistas Continuam Avançando em 2017 com suas edições digitais. PODER360, Brasília, 5 abr. 2017. Disponível em: https://www.poder360.com.br/midia/jornais-erevistas-continuam-avancando-em-2017-com-suas-edicoes-digitais/. Acesso: em 23 set. 2017.

REIS, Thiago. 80\% dos deputados federais eleitos têm ensino superior. G1, 7 out. 2014. Disponível em http://g1.globo.com/politica/eleicoes/2014/blog/eleicao-em-numeros/post/80-dos-deputadosfederais-eleitos-tem-ensino-superior.html. Acesso em: 23 set. 17.

RUBIM, Antonio. Espetacularização e midiatização da política. In: RUBIM, Antonio. (Org). Comunicação e política. Salvador: Edufba, 2004, p. 181-222.

SCAMMELL, Margaret. Election campaign communication. In: MAZZOLENI, Gianpietro. (Ed.) International Encyclopedia of Political Communication, London: John Wiley \& Sons Inc., 2016.

SECRETARIA DE COMUNICAÇÃO SOCIAL DA PRESIDÊNCIA DA REPÚBLICA. Relatório Final Pesquisa Brasileira de Mídia 2016. Brasília, 2016. 
STRÖMBÄCK, Jesper. Four phases of mediatization: an analysis of the mediatization of politics. International Journal of Press/Politics, p. 228-246, 2008.

STROMER-GALLEY, Jennifer. On-line interaction and why candidates avoid it. Journal of communication, v. 50, n. 4, p. 111-132, 2000.

TURCOTTE, Jason; YORK, Chance; IRVING, Jacob; SCHOLL, Rosanne; PINGREE, Raymond. News Recommendations from Social Media Opinion Leaders: Effects on Media Trust and Information Seeking. Journal of Computer-Mediated Communication, v. 20, n. 5, p. 520-535, 2015.

VAN AELST, Peter; SHEAFER, Tamir; STANYER, James. The personalization of mediated political communication: A review of concepts, operationalizations and key findings. Journalism, v. 13, n. 2, p. 203-220, 2012.

ZWEIR, Robert. 1979. The Search for Information: Specialists and Nonspecialists in the U.S. House of Representatives, Legislative Studies Quarterly, v. 4, n. 1, p. 31-42, 1979.

Artigo submetido em: 2018-06-13

Reapresentado em: 2018-10-30

Aceito em: 2018-11-28 